\title{
Advanced Materials Research and Development for Transport
}

The following reports summarize the discussions held during the highly successful 1985 E-MRS Fall Meeting, November 26-29, 1985, Strasbourg, France. The theme of the meeting was Advanced Materials Research and Development for Transport, which drew the attendance of 450 scientists from around the world. Meeting chairmen for this conference were W.J.G. Bunk (Cologne, West Germany) and J.G. Wurm (Brussels, Belgium). The next EMRS meeting will be held June 17-20, 1986 in Strasbourg. See the January/February 1986 issue of MRS BULLETIN for details.

\section{Symposium A: Light Metals Research} R.J.H. Wanhill, Symposium Chairman

This symposium attempted to reflect current trends and interests in materials science and engineering aspects of light alloy research and development for transport applications. The symposium consisted of 36 papers on the following topics:

- Keynote papers on aluminum alloys

- Aluminum-lithium alloys

- PM and RST aluminum alloys

- Advanced fabrication aluminum alloys I: superplastic forming and casting

- Advanced fabrication aluminum alloys II

- Magnesium alloys

- Titanium alloys

The emphasis was on aluminum alloys for two reasons: (1) the use of magnesium and titanium alloys in transport applications is significantly less than that of aluminum alloys, and (2) there had been a recent important international conference on titanium alloys in Munich, September 1984.

The keynote papers were presented by leading authorities from different sectors of the transport industry. S. Sato led off the symposium with "Present and Future of Aluminum Alloys for Transport in Japan." F. Ostermann presented the paper "Criteria for Selection of Aluminum for Modern Trains," and P.V. Kandachar discussed "Applications for Advanced Aluminum Alloys in Aircraft."

There was much interest in aluminumlithium, powder metallurgy (PM) and rapid solidification technology (RST) aluminum alloys. Fourteen papers gave a fairly even balance between fundamental and engineering aspects of these advanced materials. Applications are likely to be restricted mainly to aerospace vehicles owing to high cost.

Twelve papers were presented on advanced fabrication of aluminum alloys. The emphasis was on improved processing and fabrication of conventional alloys and less on fundamental aspects. It is clear that

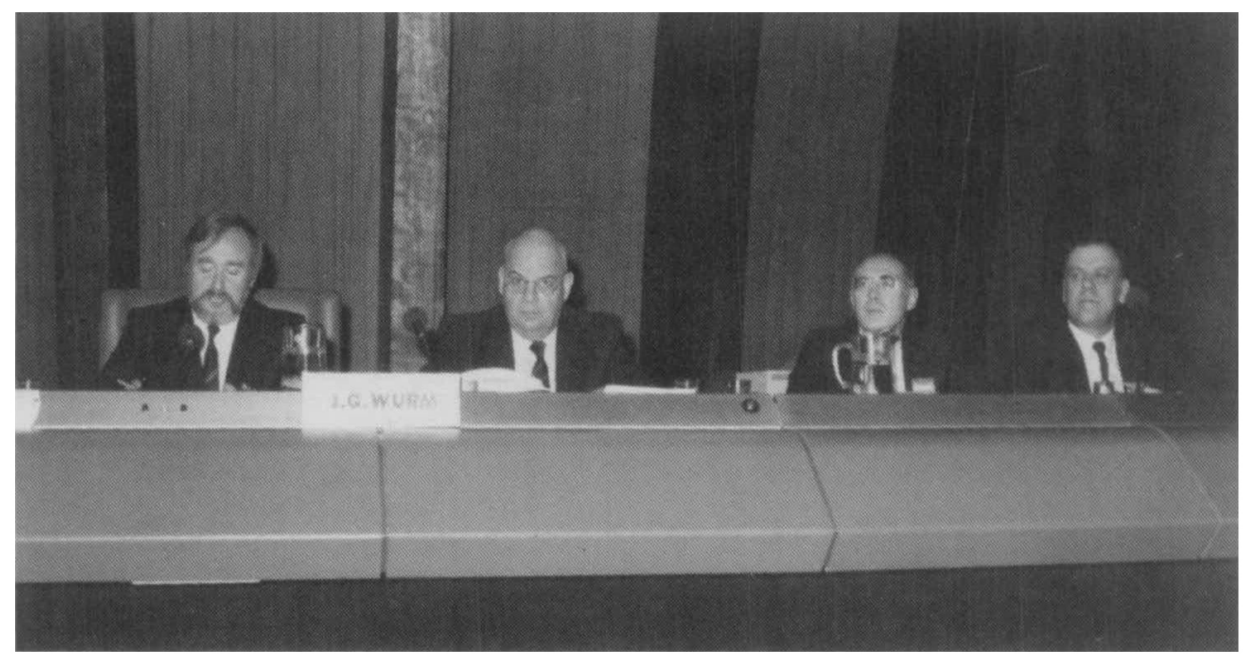

Panel opens E-MRS Meeting with discussion of political and scientific aspects of materials for transportation. Shown are (left to right): Panelist J.D. Massue (Scientific Advisor to the Parliamentary Assembly, Strasbourg, France), Panelist J.G. Wurm (Commission des Communautés Européennes, Brussels, Belgium), Symposium B Chairman P. Lamicq (Société Europienne de Propulsion, France) and Symposium C Chairman I.A. Kvernes (I.K. Engineering, Norway).

much can be done in this respect, together with improved design concepts, to make more efficient use of aluminum alloys in all forms of transport.

Four papers on magnesium alloys presented a consensus viewpoint of the major magnesium producers. The magnesium industry is making substantial efforts to increase its share of transport applications, notably by introducing new wrought and cast alloys with improved strength, elevated temperature performance and corrosion resistance. Improved corrosion protection systems have been developed also.

Last, there were three papers on titanium alloys reviewing the fundamental and engineering aspects of fatigue and fracture, and applications in the aerospace industry. The use of titanium alloys in transport is still largely confined to aircraft gas turbines and heat-resistant or high load density areas of airframes. However, titanium's high strength-to-weight ratio makes it attractive for high-speed reciprocating or rotating machinery in other forms of transport, and such applications will surely increase.

\section{Symposium B: Composites}

P. Lamica, Symposium Chairman

As the number of participants reached over 100, Symposium B, Composites, was held in the large session room of the Council of Europe. Many speakers, therefore, presented their papers from the very place where leaders from all over the world, including President Reagan, addressed the European Assembly. The scientific committee for this symposium intended to raise interest in the symposium's topic not only from research labs or institutes but also industry. This goal was reached, as about $30 \%$ of the papers were presented by industrial firms, and two sessions were devoted to parts design and development. Scientific aspects and studies on the laboratory scale were discussed during six plenary sessions and one poster session. Two sessions were devoted to basics in composites: fibers, interfaces, stacking sequences, resins, and viscoelasticity. Two dealt with new inorganic matrixes, namely ceramicceramic composites and metal-matrix composites. One discussed long-term behavior and damage, and one addressed nondestructive techniques.

Most of the sessions began with an extended invited paper, followed by three shorter papers which gave rise to some interesting discussions. Many more contacts were made during the poster session and throughout the meeting.

\section{Symposium C: Ceramic Coatings for Heat} Engines

1.A. Kvernes, Symposium Chairman

Symposium $\mathrm{C}$ on Ceramic Coatings for Heat Engines had attendance both from the industry and the universities. There was great interest in the topic, and the lectures and discussions were on a high technical level.

Continued 


\section{CONFERENCE REPORT}

\section{Continued from previous page}

In order to be able to evaluate competing materials to coatings, it was also necessary to review the state of the art for solid ceramics. It is evident that silicon-based materials are the best candidates for engine applications.

The purpose for $R \& D$ programs on thermal barrier coatings (TBCs) were twofold:

(1) Application of TBCs to critical engine parts requires more reliable coatings.

(2) Improvements are needed in current powder specifications. A brief discussion of some of the main topics from the lectures on TBCs are summarized below. These can be divided into the following points:

(1) Coating method

(2) Powder/microstructure/properties

(3) Degradation mechanisms

\section{Coating Method}

Plasma spraying seems to be the most flexible and cost-effective method for deposition of high quality ceramic. Figure 1 shows the different modifications of the plasma spray process. Physical vapor deposition and gas high-velocity spraying are also included in the figure. These methods can in some cases be an alternative process for producing ceramic coatings.

Production use of TBCs for diesel or gas turbine components requires automated plasma spray equipment. Microprocessor control of deposition parameters is necessary to reproducibly deposit the desired composition as well as obtain the relative plasma gun workpiece positioning for the necessary uniformity and coverage. Typical applications require a number of passes with the plasma gun coupled with component rotating or positioning.

Component and plasma gun manipulation in relative three-dimensional space

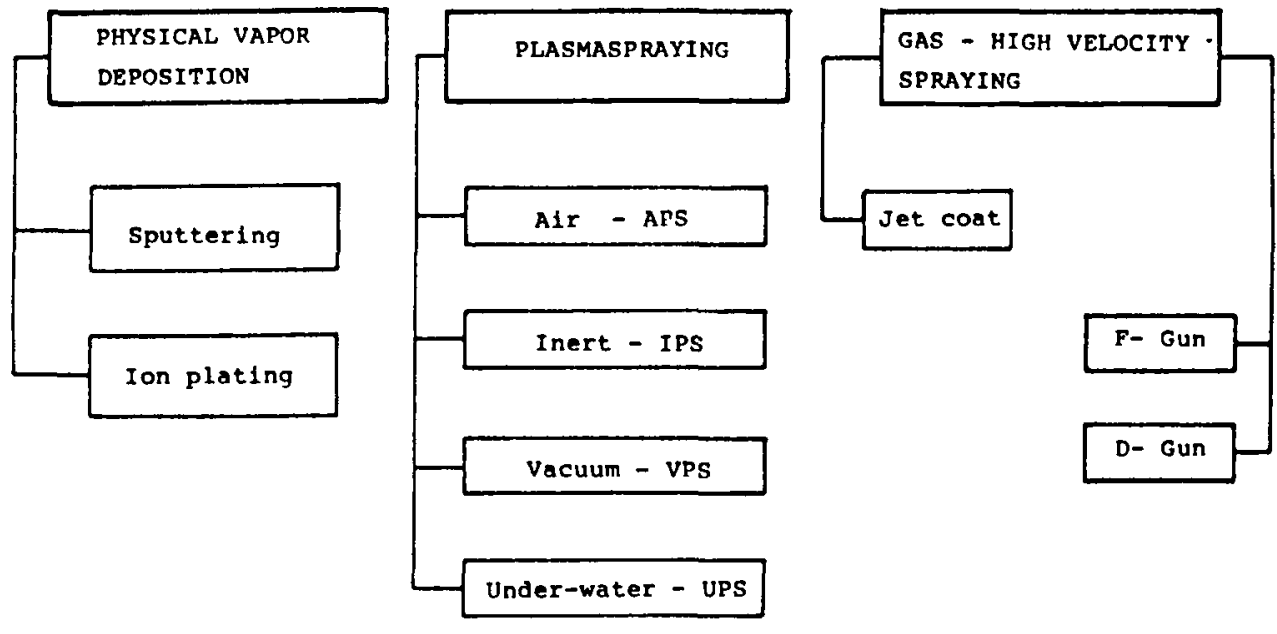

Figure 1. High energy coating methods.

requires simultaneous multi-function control, generally referred to as robotics. The rapid development of microprocessor control capabilities coupled with decreasing cost of the units are having a major impact in thermal barrier coating development.

\section{Powder/microstructure/properties}

The desire to improve the performance and thermal efficiency of diesel and gas turbine engines has led to higher operating temperatures. Coatings have the potential to accommodate these temperatures and thereby a provide dramatic increase in engine performance. This permits higher heat load on the components.

The characterization of the coating morphology as pore volume, pore size, pore surface and shape, and pore distribution is performed on a metallographically prepared sample with a computer-aided image analyser (IBAS II). This system makes it possible to emphasize through an interactive

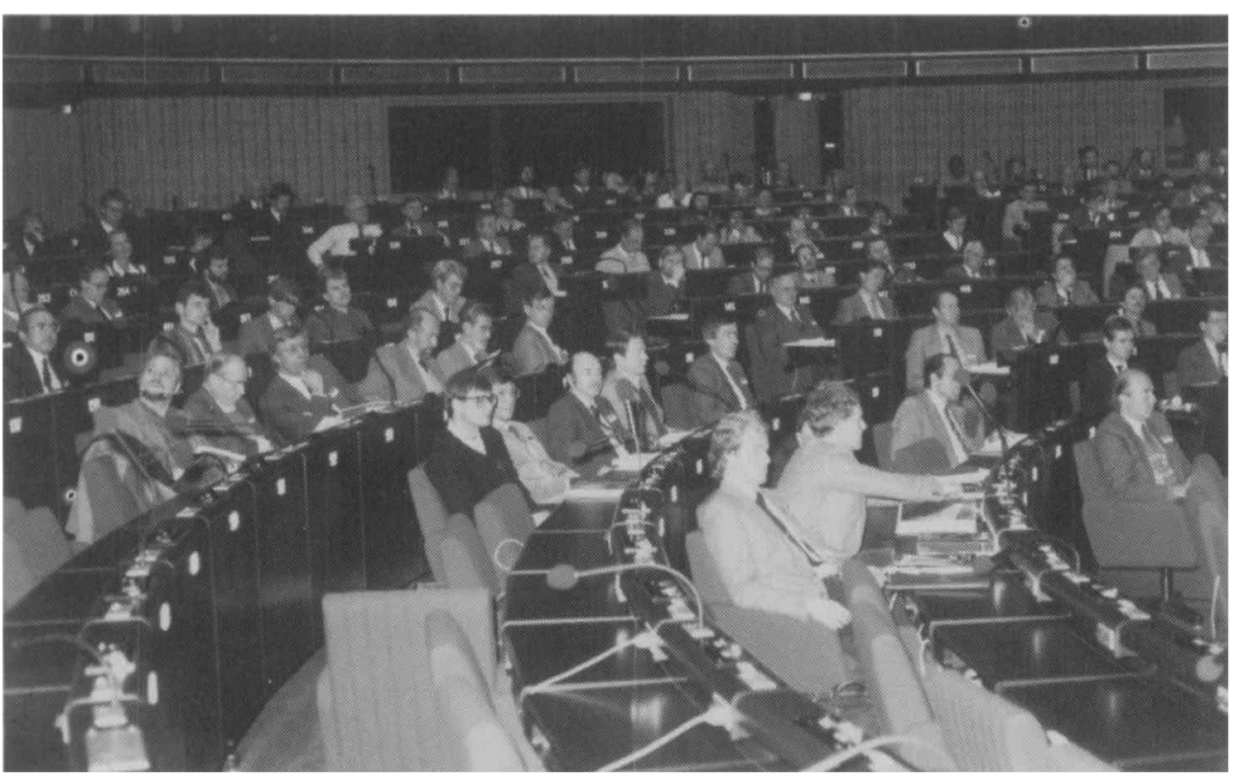

Large audience attends 1985 E-MRS Fall Meeting in Strasbourg, November 1985. picture version, the geometrical transformation of details and gray areas. A fieldand object-specific measurement can thus be made to determine the porosity, pore distribution, and pore shape in addition to other measurements to establish pore morphology.

It was reported that when choosing the correct spraying material in order to solve a stated problem, it is important to know the essential powder characteristics such as morphology, microstructure, and chemical composition. The different types of powders offered should be considered as a possibility to optimize the coating quality to different applications. According to this information the sprayed coatings depend on the powder used and the plasma process, and it is evident that quality control is of increasing importance.

It was shown that the selection of powder types for a certain coating and the proper spray process with optimized spray parameters can produce coatings with prescribed porosity and pore sizes homogeneously distributed in the coating cross section.

With a fine beam burner in the subsonic range, middle porosity with big pores can be obtained. With the same burner in the sonic area, low porosity of $5 \%$ with small pores can be obtained. With a universal burner in the sonic range, high porosities of $40 \%$ can be obtained along with relatively small pores. When low porosity is required, a sintered $Y S Z$ powder must be used for coatings in the sonic range with a fine beam burner.

Coatings which are applied in diesel engines or parts exposed to combustion gases have to be optimized for thermal shock resistance, fracture toughness, and erosion and corrosion resistance.

It is evident that the properties depend on the degree of stabilized phases and the coating microstructure which again depends

Continued 
Continued from previous page on the characteristics of the plasma process and the powder quality selected.

\section{Conclusions}

Within generic manufacturing processes, significant differences in powder characteristics exist. Powder characteristics are strongly reflected in the as-sprayed coatings, and size distribution is dominant. Thermal cyclic exposure differs from continuous thermal exposure.

\section{Degradation Mechanisms for TBC}

Frequently, spallation of thermal barrier coatings is caused by thermal expansion mismatch between the coating and the substrate. Phase transformations, corrosion, salt penetration, and mechanical wear can also contribute to degradation. The various degradation mechanisms for thermal barrier coatings are shown in Figure 2 . The weak link in the thermal barrier coating system is the interface between the oxide and the bond coating. Failures have been found to be partly caused by insufficient cohesive strength inside the ceramic and partly by defects in the bonding between the ceramic and the $\mathrm{MgCrAlY}$.

This high-temperature capability of TBC is available because of the nature of the bonding present in the ceramic, and it is the same bonding properties which are responsible for the brittle behavior invariably experienced.

The choice of ceramic coating is therefore limited because of mechanical compatibility with the substrate metal and this influences the structure of the applied
SPALLING DUE TO THERMAL CYCLING

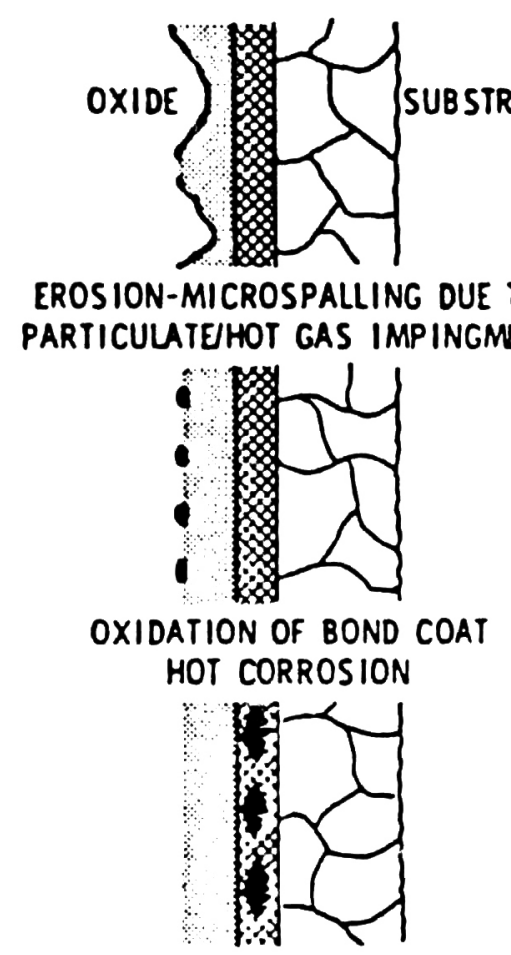

DESTABILIZATION OF $\mathrm{ZrO}_{2}$
DUE TO THERMAL CYCLING
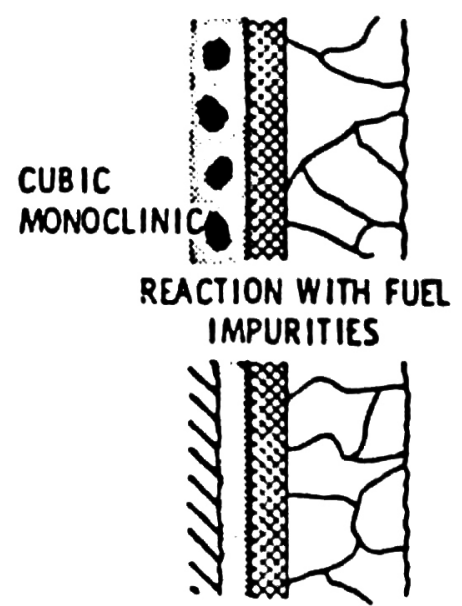

INF ILTRATE BY GASEOUS INPURITIES

\& CONDENSATION OF HIO PHASES

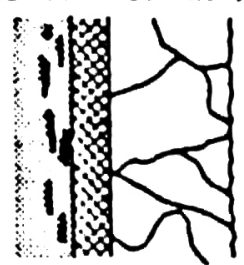

Figure 2. Some potential ceramic failure mechanisms, from S. Levine et al. (NASA).

ceramic. A dense structure may give better environmental protection but increased compatibility problems, whereas an open structure gives access of the contaminant agents to underlying metal. Further, the defect sizes that are critical for ceramic coatings are much smaller than for metals and metal coatings. Small surface irregularities can prove to be particularly damaging.

\title{
1985 Fall Meeting Program and Abstract Book
}

This compact reference which contains an index to authors and chairs is an excellent compendium to the 19 proceedings and extended abstract volumes to be published from the Meeting.

\section{Send check for $\$ 7.00$ to:}

\author{
Publications Department, Materials Research Society \\ 9800 McKnight Road \\ Suite 327 \\ Pittsburgh, PA 15237 \\ telephone (412) 367-3012
}

